\title{
MICROBIOLOGIA DA CARNE MOIDA: 1. CONTAGEM TOTAL DE BACTÉRIAS *
}

\author{
MURilo Graner ** \\ Alcides Martinelli Filho ** \\ Vivaldo F. DA CRUZ ***
}

\begin{abstract}
Como primeira etapa de um programa de estudos microbiológicos da carne moida comercializada em Piracicaba, quarenta amostras de carne bovina,. provenientes de dois tipos de estabelecimento de venda a varejo (açougue e supermercado), correspondendo a dois sistemas de distribuição de carne (um antigo e outro recente), foram analisados quanto ao número total de bactérias, segundo as recomendações da "American Public Health Association". As amostras foram obtidas semanalmente pela manhã e à tarde, durante aproximadamente dois meses. A incubação das placas de Petri foi feita a $21^{\circ} \mathrm{C}$ (72 horas) e a $32^{\circ}$ (48 horas). Os resultados podem ser resumidos como segue: 1) Contagens totais elevadas foram, em geral, observadas, com diversas amostras na faixa de $10^{7}$ a $10^{9}$ bactérias/grama; as médias obtidas foram 6,9 × $10^{7}$ $\left(21^{\circ} \mathrm{C}\right)$ e $2,5 \times 10^{7}\left(32^{\circ} \mathrm{C}\right)$ bactérias por grama. 2) A incubação feita a $21^{\circ} \mathrm{C}$ resultou, em geral, em contagens mais elevadas que as correspondentes à temperatura de incubação de $32^{\circ} \mathrm{C}$; todavia, a diferença observada não foi estatìsticamente significativa. 3) As contagens obtidas para as amostras correspondentes ao sistema antigo de distribuição de carne foram significativamente mais elevadas que as correspondentes ao sistema recente, o que se relacionou com contagens mais elevadas obtidas para as amostras coletadas pela manhã no estabelecimento menor.
\end{abstract}

\section{INTRODUÇÃO}

Tecido muscular livre ou quase livre de microrganismos tem sido obtido por diferentes métodos, em estudos visando separar as alterações de natureza microbiológica daquelas de natureza enzimática e/ou química, ou então em estudos sobre o efeito de determinados microrganismos no tecido muscular (OCKERMAN, 1970). Os diversos trabalhos realizados demonstram ainda que a contaminação da carne durante as operações de abate e outras realizadas posteriormente tem grande importancia em relação ao número de microrganismos encontrados na carne e à sua deterioração. As fontes de contaminação

\footnotetext{
* Entregue para publicação em 9-12-1971.

** Departamento de Tecnologia Rural da ESALQ.

*** Departamento de Matemática da ESALQ.
} 
de carne foram discutidas por AYRES (1955) e por FRAZIER (1967), entre outros autores.

Segundo ROGERS e Mc CLESKEY (1957), a carne moida constitui meio altamente favorável para a multiplicação de bactérias, em virtude da fragmentação dos tecidos, com liberação de suco celular, e da incorporação dos microrganismos (normalmente, encontrados na superfície) à carne. A população bacteriana da carne moida depende da qualidade, sob o ponto-de-vista microbiológico, da matéria prima utilizada no seu preparo, da limpeza do equipamento empregado, do tempo e da temperatura de armazenamento. Em levantamento feito pelos autores, analisando 96 amostras de carne (bovina) moida, foram encontrados valores médios variando de $1,6 \times 10^{6}$ a $2,3 \times 10^{8}$ bactérias/grama, para uma temperatura de incubação das placas de Petri de $37^{\circ}$ (dois dias) e de $3,9 \times 10^{6}$ a $1,1244 \times 10^{9}$ bactérias/grama para uma incubação feita a $7^{\circ} \mathrm{C}$ ( 7 dias). As médias gerais, para ambas as temperaturas de incubação, foram, respectivamente, $3,28 \times 10^{7}$ e $1,925 \times 10^{8}$ bactérias/grama. Em geral, as amostras obtidas em estabelecimentos grandes apresentaram contagens mais baixas que as obtidas em pequenos estabelecimentos.

JAY (1964), analisando 26 amostras de carne (bovina) moida, obteve contagens variando de $10^{5,57}$ a $10^{8,67}$ bactérias/grama, para uma incubação das placas a $30^{\circ} \mathrm{C}$ ( 3 dias), com uma média de $10^{6,72}$ bactérias/grama, por ocasião da trituração; quando a deterioração da carne foi detectada pelo olfato, os valores encontrados foram de $10^{7,15}$ a $10^{9,9}$ bactérias/grama, sendo a média de $10^{8,48}$ bactérias/grama.

FOSTER (1966) discutiu o valor da contagem total de microrganismos no estabelecimento de padrões microbiológicos para os alimentos e a importância da metodologia envolvida. Um número elevado de microrganismos, encontrado na carne, não significa que o alimento é, obrigatòriamente, prejudicial à saúde do consumidor. Assim, por exemplo, se uma carne de ótima qualidade sob o ponto-de-vista microbiológico, fôr armazenada a cêrca de $0^{\circ} \mathrm{C}$ por longo tempo, deverá a mesma apresentar, após êsse período, contagem total de bactérias elevada, em virtude da multiplicação de microrganismos psicrofílicos ; nessa temperatura, todavia, as bactérias potencialmente causadoras de envenenamento ou infecção alimentares não desenvolvem atividade ou se multiplicam (EVANS e NIVEN, 1960; FRAZIER, 1967). Por outro lado, uma contagem total de bactérias baixa não significa que o alimento é, obrigatòriamente, livre de efeitos nocivos sôbre a saúde do consumidor. Contudo, uma contagem bacteriana elevada na carne moida poderá ser indício de um produto alterado, sob o ponto-de-vista microbiológico, ou semi-deteriorado, independentemente do efeito que o mesmo possa ter sôbre a saúde do consumidor (ROGERS e Mc CLESKEY, 1957). 
Recentemente, decreto do Govêrno do Estado de S. Paulo (N.o 52.504 , de 28/7/70) estabeleceu, para a "carne crua exposta à venda como carne crua preparada ou moida" o limite de $5 \times 10^{5}$ "bactérias vivas mesófilas aeróbias saprófitas" por grama, sem especificar, entretanto, o método para essa determinação.

No presente trabalho, o primeiro de um programa de estudos microbiológicos da carne moida comercializada em Piracicaba, quarenta amostras de carne bovina, moida, obtidas em dois tipos de estabelecimentos (açougue e supermercado), em dois horários (de manhão e à tarde), durante cêrca de dois mêses, foram analisados, quanto à contagem total de bactérias pelo método de contagem em placas; foi observado também o efeito do binômio temperatura-tempo de incubação sôbre os valores obtidos. Foi escolhida a carne moida para aqueles estudos pelo fato de constituir o produto meio mais favorável à multiplicação de microrganismos que a carne não moida, e por ser uma fonte mais barata de proteína de boa qualidade, uma vez que pode ser preparado com partes da carcaça de menor valor comercial ou com retalhos de carne.

\section{MATERIAL E MÉTODOS}

Quarenta amostras de carne (bovina) moida foram obtidas em estabelecimentos localizados na cidade de Piracicaba, os quais podem ser caracterizados como segue - Estabelecimento A, açougue, comercializando carne proveniente de animais abatidos em matadouro municipal; Estabelecimento B, supermercado, comercializando carne proveniente de animais abatidos em frigorífico da região. No primeiro, a carne era moida à vista do consumidor, na medida da solicitação, enquanto no supermercado a carne encontrava-se exposta à venda, em mostruário refrigerado. As amostras, consistindo em porções de 250 gramas, foram obtidas semanalmente, às terças-feiras (em três das semanas também às quintas-feiras), às 8 e às 13 horas, de meados de abril e meados de junho de 1971.

A análise microbiológica (contagem total de bactérias) foi realizada segundo o método recomendado pela "American Public Health Association" (SHARF, 1966). Cada amostra, imediatamente após sua obtenção, foi levada para o laboratório e moida três vêzes em moedor de carne elétrico, esterilizado em autoclave, através de disco com orifícios de $5 \mathrm{~mm}$ de diâmetro. Uma suspensão de $11 \mathrm{~g}$ da amostra em $99 \mathrm{ml}$ de diluente apropriado foi preparada em liquidificador "Waring". Rediluições foram feitas a partir dessa suspensão, sendo preparadas 6 placas de Petri para cada rediluição: 3 para incubação a $21^{\circ} \mathrm{C}$ por 72 horas e 3 para incubação a $32^{\circ} \mathrm{C}$ por 48 horas. Após o período de incubação, o número de colônias por placa foi determinado com auxílio de um contador de colônias "Quebec", sendo considera- 
das para contagem as placas apresentando um número de colônias de 30 a 300.

Para efeito de análise estatística, os valores encontrados (x. $10^{5}$ bactérias/grama) foram convertidos nos respectivos logarítmos neperianos $(\mathrm{y}=\mathrm{Lx})$. A análise de variância foi realizada conforme o esquema de um fatorial $2 \times 2 \times 2$, com 10 blocos (semanas) e 3 contagens por parcela para todo o conjunto de valores; e, em seguida, conforme o esquema de um fatorial $2 \times 2$, com 10 blocos (semanas) e 3 contagens por parcela, para os dados correspondentes aos dois estabelecimentos, separadamente (GOMES, 1970).

As contagens totais de bactérias (x. $10^{5}$ bactérias/grama) médias para os diferentes blocos (semanas), após transformação em logarítmos neperianos $(\mathrm{y}=\mathrm{Lx})$ foram comparadas com dados meteorológicos (temperaturas máxima, mínima e média e umidade relativa do ar nos dias de amostragem e imediatamente anterior), fornecidos pelo Departamento de Física e Meteorologia da ESALQ.

\section{RESULTADOS E DISCUSSÃO}

Pelo exame do Quadro 1, podemos ver que a contagem total de bactérias variou conforme segue:

Estabelecimento $\mathbf{A}=$ de $4,3 \times 10^{5}$ a $6,9133 \times 10^{8}$ bactérias/grama (média de 1,0027 x $10^{8}$ bactérias/grama) para a temperatura de incubação de $21^{\circ} \mathrm{C}$ : de $8,9 \times 10^{5}$ a $3.0650 \times 10^{8}$ bactérias/grama (média de $4,409 \times 10^{7}$ bactérias/grama ) para a incubação teita a $32^{\circ} \mathrm{C}$.

Estabelecimento $\mathbf{B}=$ de $4,6 \times 10^{5}$ a $1,5833 \times 10^{8}$ bactérias/grama (média de 2,156 $\times 10^{7}$ bactérias/grama), para a temperatura de incubação de $21^{\circ} \mathrm{C}$; de $1,17 \times 10^{6}$ a 2,363 x $10^{7}$ bactérias/grama (média 5,48 x $10^{6}$ bactérias/grama) para a incubação feita a $32^{\circ} \mathrm{C}$.

Embora, em média, os valores encontrados para a temperatura de incubação de $21^{\circ} \mathrm{C}$ ( 72 horas) fôssem maiores que os obtidos para a incubação feita a $21^{\circ} \mathrm{C}$ (48 horas), a análise estatística dos resultados (Quadro 2 e Figura 1) não mostram diferença sıgnıticativa entre as duas temperaturas, as quais constituem alternativas apresentadas pela "American Public Health Association" (SHARF, 1966) para a análise microbiológica (contagem total de bactérias) da carne fresca.

A análise estatística dos resultados mostram diferença significativa ao nível de $1 \%$ de probabilidade entre os estabelecimentos $\mathbf{A}$ e $\mathbf{B}$ e, para o primeiro, entre as amostras coletadas às 8 horas e as coletadas às 13 horas (Quadros 2 e 3 e Figura 1). Pode-se notar que a diferença existente entre os dois estabelecimentos foi devida ao fato de apresentarem as amostras obtidas em $\mathbf{A}$ pela manhã maior número 
QUADRO 1 - Contagem total de bactérias (x.105 bactérias/grama); os valores apresentados são médias resultantes da contagem de 3 placas.

\begin{tabular}{|c|c|c|c|c|c|c|c|}
\hline \multicolumn{4}{|c|}{ Estabelecimento A } & \multicolumn{4}{|c|}{ Estabelecimento B } \\
\hline \multicolumn{2}{|c|}{8 horas } & \multicolumn{2}{|c|}{13 horas } & \multicolumn{2}{|c|}{8 horas } & \multicolumn{2}{|c|}{13 horas } \\
\hline $21^{\circ} \mathrm{C}$ & $32^{\circ} \mathrm{C}$ & $21^{\circ} \mathrm{C}$ & $32^{\circ} \mathrm{C}$ & $21^{\circ} \mathrm{C}$ & $32^{\circ} \mathrm{C}$ & $21^{\circ} \mathrm{C}$ & $32^{\circ} \mathrm{C}$ \\
\hline 3250,0 & 1367,7 & 2116,7 & 1383,3 & 198,3 & 67,7 & 1583,3 & 236,3 \\
\hline 1323,0 & 643,3 & 119,3 & 136,3 & 726,7 & 25,3 & 730,0 & 144,7 \\
\hline 3526,7 & 317,0 & 75,3 & 48,7 & 150,3 & 21,0 & 300,3 & 72,3 \\
\hline 247,0 & 115,3 & 153,7 & 26,0 & 15,9 & 25,8 & 16,1 & 24,3 \\
\hline 107,3 & 1086,7 & 4,3 & 8,9 & 153,7 & 28,3 & 16,3 & 14,3 \\
\hline 16,5 & 26,0 & 4,8 & 13,2 & 17,8 & 28,6 & 15,3 & 26,8 \\
\hline 6913,3 & 3065,0 & 1940,0 & 247,3 & 30,1 & 121,3 & 7,5 & 13,6 \\
\hline 22,9 & 72,3 & 29,0 & 13,2 & 75,7 & 26,4 & 4,6 & 11,7 \\
\hline 193,7 & 176,3 & 12,5 & 20,0 & 157,0 & 99,0 & 91,7 & 76,7 \\
\hline 77,7 & 28,4 & 20,3 & 14,2 & 11,9 & 17,1 & 10,5 & 16,2 \\
\hline 1567,8 & 690,8 & 447,6 & 191,1 & 153.7 & 46,0 & 277,6 & 63,7 \\
\hline
\end{tabular}

QUADRO 2 - Análise da variância dos valores obtidos na contagem total de bactérias ( $\mathrm{x} .10^{5}$ bactérias/grama), após sua transformação em logarítmos neperianos $(\mathrm{y}=\mathrm{L} \mathrm{x})$.

\begin{tabular}{|c|c|c|c|}
\hline Fonte de Variação & GL & $\mathrm{QM}$ & $\mathrm{F}$ \\
\hline $\begin{array}{l}\text { Estabelecimentos (E) } \\
\text { Horários (H) } \\
\text { Temperaturas de incubação }(\mathrm{T}) \\
\text { E } \times \text { H } \\
\text { E } \times \mathrm{T} \\
\mathrm{H} \times \mathrm{T} \\
\mathrm{E} \times \mathrm{H} \times \mathrm{T}\end{array}$ & $\begin{array}{l}1 \\
1 \\
1 \\
1 \\
1 \\
1 \\
1\end{array}$ & $\begin{array}{r}57,7858 \\
55,9285 \\
8,8140 \\
33,2993 \\
0,3061 \\
0,5469 \\
1,0549\end{array}$ & $\begin{array}{l}13,95++ \\
13,50++ \\
2,13 \\
8,04++ \\
0,07 \\
0,13 \\
0,25\end{array}$ \\
\hline $\begin{array}{l}\text { Fatorial } 2 \times 2 \times 2(\mathrm{~F}) \\
\text { Blocos (B) } \\
\mathrm{F} \times \mathrm{B} \text { (Resíduo a) }\end{array}$ & $\begin{array}{c}(7) \\
9 \\
63\end{array}$ & $\begin{array}{r}38, \overline{5775} \\
4,1430\end{array}$ & $\overline{9,31+}+$ \\
\hline $\begin{array}{l}\text { Parcelas } \\
\text { Contagem dentro de parcelas (Resíduo b) }\end{array}$ & $\begin{array}{r}79 \\
160\end{array}$ & $\overline{0,0209}$ & $\overline{-}$ \\
\hline Total & 239 & $\begin{array}{l}\text { Média geral } \\
\text { C.V. (a) } \\
\text { C.V. (b) }\end{array}$ & $\begin{array}{l}=4,3134 \\
=47 \% \\
=3 \%\end{array}$ \\
\hline
\end{tabular}


QUADRO 3 - Análise da variância dos dados obtidos na contagem total de bactérias (x.105 bactérias/grama), após sua transformação em logarítmos neperianos, para os Estabelecimentos A e B.

\begin{tabular}{|c|c|c|c|c|c|}
\hline \multirow{2}{*}{ Fonte de Variação } & \multirow{2}{*}{ GL } & \multicolumn{2}{|c|}{ A } & \multicolumn{2}{|c|}{$\mathrm{B}$} \\
\hline & & $\mathrm{QM}$ & $F$ & $\mathrm{QM}$ & $\mathrm{F}$ \\
\hline $\begin{array}{l}\text { Horários }(\mathrm{H}) \\
\text { Temperaturas de incubação }(\mathrm{T}) \\
\mathrm{H} \times \mathrm{T}\end{array}$ & $\begin{array}{l}1 \\
1 \\
1\end{array}$ & $\begin{array}{r}87,7669 \\
2,9173 \\
0,0415 \\
\end{array}$ & $\begin{array}{l}32,43++ \\
1,08 \\
0,015\end{array}$ & $\begin{array}{l}1,4581 \\
6,2025 \\
1,5626\end{array}$ & $\begin{array}{l}0,49 \\
2,09 \\
0,53\end{array}$ \\
\hline $\begin{array}{l}\text { Fatorial } 2 \times 2 \\
\text { Blocos } \\
\text { Resíduo a }\end{array}$ & $\begin{array}{c}(3) \\
9 \\
27\end{array}$ & $\begin{array}{r}-\overline{36,3909} \\
2,7066 \\
\end{array}$ & $13, \overline{4}++$ & $\begin{array}{r}\overline{14,1920} \\
2,9586 \\
\end{array}$ & $\begin{array}{c}\overline{-}, \overline{9+}+ \\
- \\
\end{array}$ \\
\hline $\begin{array}{l}\text { Parcelas } \\
\text { Contagem dentro de parcelas (b) }\end{array}$ & $\begin{array}{l}39 \\
80 \\
\end{array}$ & 二 & $\overline{-}$ & $\overline{-}$ & $\overline{-}$ \\
\hline Total & 119 & - & - & - & - \\
\hline $\begin{array}{l}\text { Média geral } \\
\text { C.V. (a) } \\
\text { C.V. (b) } \\
\end{array}$ & & $\begin{array}{r}4,8040 \\
34 \% \\
3 \%\end{array}$ & & $\begin{array}{r}3,8227 \\
45 \% \\
4 \%\end{array}$ & \\
\hline
\end{tabular}

QUADRO 4 - Contagens totais de bactérias (x.105 bactérias/g) médias para os diferentes blocos (semanas), após sua transformação em logarítimos neperianos $(\mathrm{y}=\mathrm{Lx})$ e dados meteorológicos correspondentes aos dias de análise e imediatamente anterior (médias de dois dias).

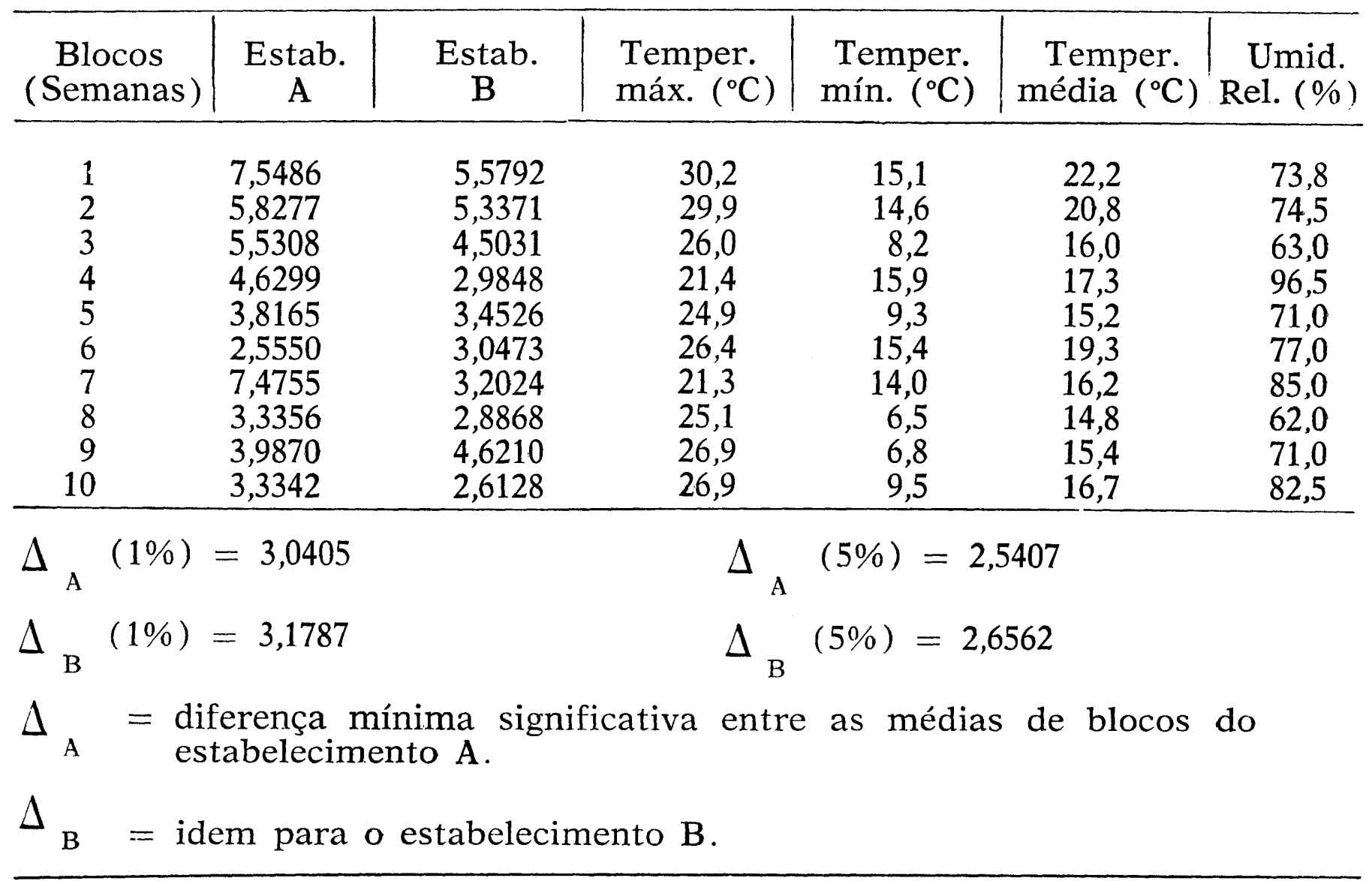




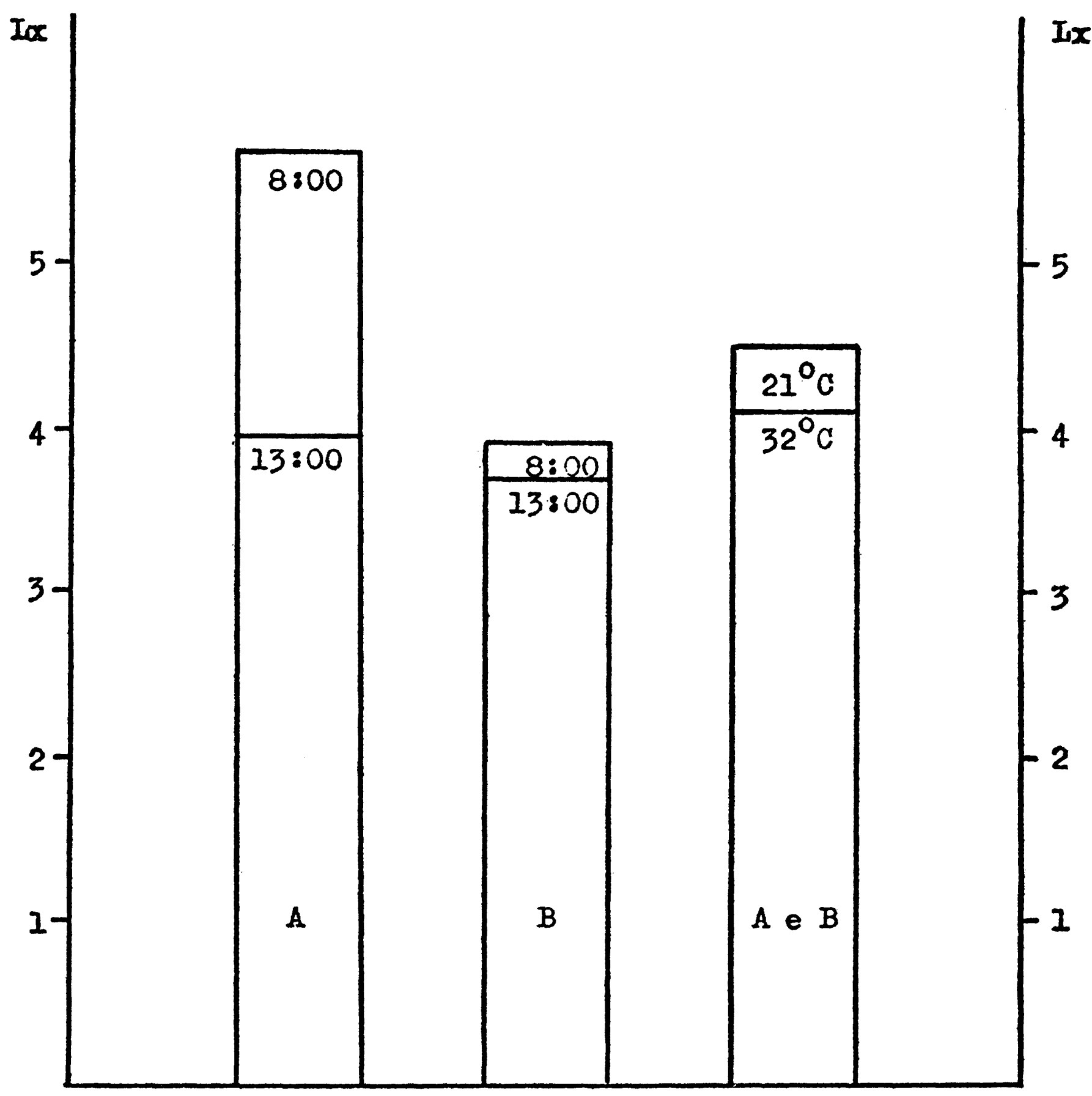

Figura 1 - Médias logarítmicas das contagens totais de bactérias (x. $10^{5}$ bactérias/grama) correspondentes aos Estabelecimentos A e B ( 8 e 13 horas( e às temperaturas de incubação de $21^{\circ} \mathrm{C}$ e $32^{\circ} \mathrm{C}$.

de bactérias/grama que as obtidas no mesmo estabelecimento às 13 horas ou em $\mathbf{B}$, em qualquer dos horários. Essa diferença parece sugerir que a assepsia, como método de conservação de carnes, era menos adequada em A que em $\mathrm{B}$, inclusive a limpeza do equipamento após o trabalho, havendo então a possibilidade de multiplicação dos microrganismos em resíduos de alimentos durante a noite e uma pesada recontaminação da carne, ao ser a mesma trabalhada pela manhã.

Conforme mostram o Quadro 1 e a Figura 2, para várias amostras foram obtidas contagens totais de bactérias superiores a $10^{7}$ e mesmo 


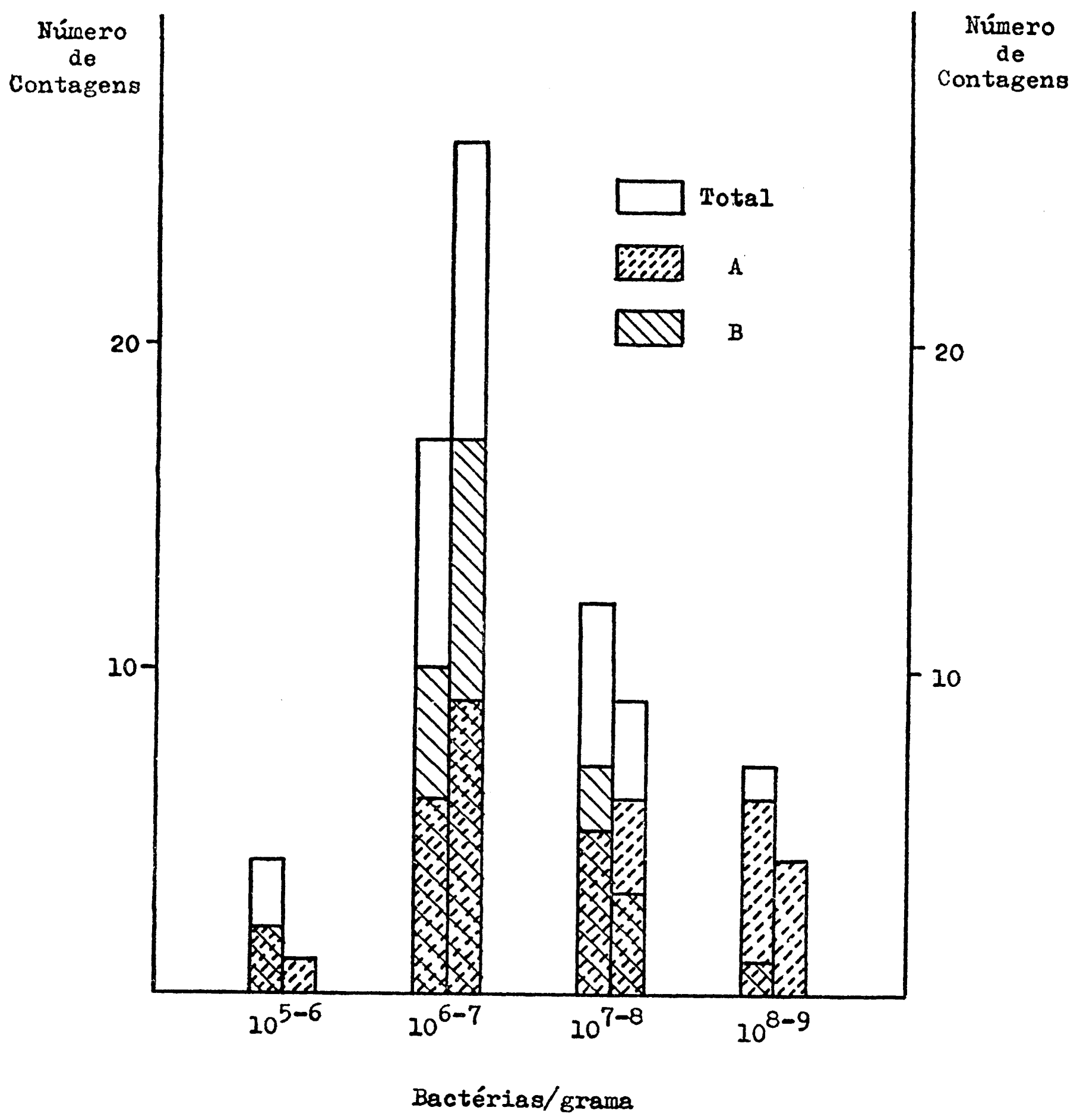

Figura 2 - Freqüências de contagens totais de bactérias obtidas para 40 amostras de carne moída nos Estabelecimentos $\mathbf{A}$ e $\mathbf{B}$, para incubações feitas a $21^{\circ} \mathrm{C}$ (coluna da esquerda) e a $32^{\circ} \mathrm{C}$ (coluna da direita).

a $10^{8}$ bactérias/grama, neste caso principalmente para as amostras provenientes de um dos estabelecimentos (A). Todavia, por ocasião da análise, a presença de odores francamente ácidos ou pútridos, indicativos de deterioração, não foi notada em nenhuma das amostras. Segundo JAY (1964), é mais difícil a percepção da deterioração pelo olfato ou pela vista (crescimento microbiano superficial) na carne moida em relação à carne não moida, em virtude da maior área superficial apresentada por aquela, sendo necessário um maior número de microrganismos. 
A diferença significativa entre as contagens realizadas nas diferentes semanas (blocos) poderia estar associada a diferenças de temperatura e/ou umidade relativa do ar. Na comparação dos valores médios obtidos semanalmente para os estabelecimentos $\mathbf{A}$ e $\mathbf{B}$ com os dados meteorológicos correspondentes aos dias de amostragem e imediatamente anterior (médias dos dois dias), foi encontrada uma correlação positiva, significativa ao nível de $5 \%$ de probabilidade $(\mathrm{r}=$ $0,71)$, entre as contagens e a temperatura máxima, para o estabelecimento B. Por outro lado, não foi encontrada correlação alguma entre as mesmas variáveis para o estabelecimento $\mathbf{A}$.

A população microbiana encontrada na carne depende de sua contaminação pelos microrganismos, em seus aspectos quanti e qualitativo, e das condições a que é submetido o alimento, entre outros fatores. Constituem fontes de contaminação da carne o exterior do animal (couro, pelos, cascos), onde se encontram microrganismos provenientes do solo, de matéria fecal e de outras origens; o interior do tubo digestivo; a água e o ar; o equipamento e o pessoal que entram em contacto direto com o alimento (AYRES, 1955; FRAZIER, 1967). Por outro lado, a carne pode deteriorar-se duas vêzes mais ràpidamente a $5^{\circ} \mathrm{C}$ que a $0^{\circ} \mathrm{C}$ (EVANS e NIVEN, 1960).

Sob o ponto-de-vista da saúde do consumidor, conforme lembrou FOSTER (1966), a mesma não é, obrigatoriamente, prejudicada pelo consumo de uma carne com elevada contagem total de bactérias. É preciso levar em consideração, todavia, que microrganismos potencialmente causadores de envenenamentos e infecções alimentares podem multiplicar-se a temperaturas superiores a $3^{\circ} \mathrm{C}$ e que a carne não é, em geral, submetida a uma adequada refrigeração em nosso meio, durante a sua distribuição.

Os resultados parecem indicar que a assepsia e o emprego adequado do frio, como métodos em conservação de carnes, poderiam contribuir para a melhoria, sob o ponto-de-vista microbiológico, da qualidade da carne moída comercializada em Piracicaba, no sentido de ser entregue ao consumidor um produto que não esteja microbiologicamente alterado e/ou possa ter um período maior de estabilidade nos estabelecimentos de venda a varejo e na geladeira do consumidor.

\section{Microbiology of Ground Beef : I. Total Bacterial Count. SUMMARY}

As a first step in a program of evaluation of ground beef microbiological quality in the city of Piracicaba, SP, forty samples of ground beef were taken at two kinds of retail markets (meat shop 
and supermarket), related to an old and a new system of meat merchandising. The samples were taken weekly in the morning and in the afternoon, during a two month period. Total bacterial counts were determined by a procedure recommended by the American Public Health Association and p'ates were incubated at $21^{\circ} \mathrm{C}(72$ hours) and at $32^{\circ} \mathrm{C}$ ( 48 hours). The results can be summarized as follows $=1$ ) Total counts were generally high, with several samples in the range $10^{7}$ to $10^{9}$ cells/gram; average counts were $6.9 \times 10^{7}$ cells/gram $\left(21^{\circ} \mathrm{C}\right)$ and $2.5 \times 10^{7}$ cell/gram $\left(32^{\circ} \mathrm{C}\right)$. 2) Incubation at $21^{\circ} \mathrm{C}$ resulted in total counts generally higher than those found at $32^{\circ} \mathrm{C}$, although there was no statistically significant difference between the two incubation temperatures. 3) Total counts were found to be higher in samples from the small shop (old system) than in samples from the supermarket (new system); the difference was related to higher counts in the morning samples taken at the former retail market.

\section{LITERATURA CITADA}

AYRES, J. C. 1955. Microbiological implications in the handling, slaughtering, and dressing of meat animals. Adv. Food Research 6:110-161.

EVANS, J. B. e C. F. NIVEN, Jr. 1960. Microbiology of meat = Bacteriology. Em American Meat Institute. 1960. The Science of Meat and Meat Products. W. H. Freeman, São Francisco, Cal. pp. 151-179.

FOSTER, E. M. 1966. Microbiological standards for foods. Proceedings of the Meat Industry Research Conference, University of Chicago. pp. 87-95.

FRAZIER, W. C. 1967. Food Microbiology Mc Graw - Hill Book Company, Nova York, N. Y. pp. 252-282.

GOMES, F. P. 1970. Curso de Estatística Experimental, 4. ${ }^{a}$ Ed. Livraria Nobel, São Paulo.

JAY, J. M. 1964. Beef microbial quality determined by extract-release volume (ERV). Food Tecnology 18: 1637-1641.

OKERMAN, H. W. 1970. Germ - free tissue = A new meat research tool. Proceedings of the Meat Industry Research Conference, University of Chicago. pp. 69-90.

ROGERS, R. E. e C. S. Mc CLESKEY. 1957. Bacteriological quality of ground beef in retail markets. Food Technology 11:318-320.

SHARF, J. M., ed. 1966. Recommended Methods for the Microbiological Examination of Foods. American Public Health Association, Inc. Nova York, N. Y. pp. 111-118. 